CARDIOVASCULAR MEDICINE

\title{
Relation between aortic stiffness and left ventricular diastolic function in patients with hypertension, diabetes, or both
}

\author{
M Eren, S Gorgulu, N Uslu, S Celik, B Dagdeviren, T Tezel
}

Heart 2004;90:37-43

See end of article for authors' affiliations

\section{Correspondence to:} Dr Sevket Gorgulu, Siyami Ersek Cardiothoracic Surgery Center, Cardiology Department, Istanbul, Turkey; sevket5@yahoo.com

Accepted 29 May 2003

\begin{abstract}
Objective: To evaluate aortic function and its relation to left ventricular diastolic function in patients with hypertension, diabetes, or both, without coronary artery disease.

Methods: Study groups were composed of 27 healthy participants and 25 patients with hypertension, 24 with diabetes, and 18 with hypertension and diabetes. Coronary artery disease was excluded in all of the study participants. Aortic strain and distensibility were calculated from the aortic diameters measured by echocardiography and blood pressure obtained by sphygmomanometry.

Results: There were significant differences between the control and the patient groups (hypertensive, diabetic, and diabetic-hypertensive) in aortic strain (mean (SD) $18(8) \%$ v $11(7) \%, 9(3) \%$, and $8(3) \%$, respectively, $p<0.001)$ and distensibility (10 (5.1) v $3.1(1.5), 5.1(2.8)$, and $2(0.9) \mathrm{cm}^{2} / \mathrm{dyn} / 10^{3}$, respectively, $\mathrm{p}<0.001$ ). In a multivariate analysis, the parameter most closely related to the deceleration time in the control group was aortic distensibility (standardised $\beta$ coefficient $-0.50, p=0.002$, overall $R^{2}=0.25$ ). In the patient group, the parameter most closely related to deceleration time was also aortic distensibility (standardised $\beta$ coefficient $-0.36, p=0.009$, overall $R^{2}=0.13$ ). Even though the study group variable was entered in to the multivariate model, aortic distensibility was found to be the parameter most closely related to deceleration time (standardised $\beta$ coefficient $-0.48, \mathrm{p}<0.001$, overall $R^{2}=0.22$ ). Conclusion: Aortic stiffness is increased in patients with hypertension, diabetes, or both even after the exclusion of coronary artery disease. Aortic stiffness and left ventricular diastolic dysfunction are also associated in these patients.
\end{abstract}

$M$ any studies have examined the effect of cardiovascular risk factors on the vessels. It is also recognised that these factors cause structural alteration, which leads to stiffness in large arteries. In particular, arterial stiffness in large arteries has been reported to be the best predictor of cardiovascular morbidity and mortality. ${ }^{1}$

Pulse wave velocity, measured either invasively or noninvasively, has been used in previous studies that have investigated arterial stiffness. ${ }^{2}{ }^{3}$ Even if the pulse wave can be recorded by the Doppler technique, measuring the distance that the pulse wave travels is a serious problem. The superficial measurement method suggested for measuring this distance has some disadvantages, such as having to correct for age and the effects of fat, breast size, and thoracic or spinal abnormalities. ${ }^{4-6}$ In addition, this method does not give the true distance. To obtain the true distance, invasive and angiographic methods must be used. Thus, the use of pulse wave velocity is difficult in practice. In this respect, it has been suggested that aortic strain and distensibility should be calculated from the aortic diameters measured by echocardiography and blood pressure obtained by sphygmomanometry. ${ }^{7}$

Left ventricular mass increases in normotensive patients with diabetes and diastolic dysfunction occurs. ${ }^{8} 9$ In addition, it is well known that diabetes increases aortic stiffness. ${ }^{10}$ Similar results have been reported in hypertensive patients. ${ }^{11-14}$ From this point of view, it seems that there is a possible relation between aortic stiffness and left ventricular diastolic dysfunction. Also, it has been reported that aortic stiffness influences left ventricular structure and function, independent of arterial blood pressure. ${ }^{15}$ These studies evaluated systolic function but did not assess the relation between aortic stiffness and diastolic function.

It has been shown that aortic stiffness increases in patients with coronary artery disease. ${ }^{16}{ }^{17}$ Thus, studies of aortic stiffness ${ }^{10-14}$ in patients with diabetes mellitus or hypertension have been limited by not excluding patients with coronary artery disease or excluding them only if they have had a history of coronary artery disease. In this regard, the present study aimed at determining, by using current methods to exclude coronary artery disease, how aortic stiffness is affected in patients with hypertension, diabetes, or both, and to evaluate the relation between aortic stiffness and left ventricular diastolic function.

\section{METHODS}

\section{Study patients}

Exclusion criteria were severe hypertension (stage 3); renal failure; more than a trace of associated valve regurgitation; associated aortic stenosis with a mean gradient $\geqslant 25 \mathrm{~mm} \mathrm{Hg}$ or moderate to severe mitral stenosis (mitral valve area $<1.5 \mathrm{~cm}^{2}$ ); ejection fraction $<55 \%$; known coronary artery disease or a laboratory test suggesting coronary artery disease, such as a positive exercise ECG, abnormal myocardial perfusion scintigraphy, or abnormal coronary arteries on angiography; familial hypercholesterolaemia; previous stroke; chronic obstructive pulmonary disease; receiving oral contraception or hormone replacement therapy; intermittent claudication; arrhythmias; and aortic disease (aneurysm, Marfan's syndrome, coarctation and aortic surgery, etc). In addition, seven patients whose aorta were poorly visualised on echocardiography were excluded

Except for 11 patients, all of the study population comprised patients who were referred to coronary angiography for angina. Arteriography was indicated and performed by cardiologists who were not involved in this study. Eleven patients were chosen from among patients who applied to our general cardiology polyclinic. On this basis, 24 patients with diabetes, 25 with hypertension, and 18 with both were enrolled in this study. In addition, the control group 
comprised 27 healthy patients who had had normal coronary arteriography and had presented with no other cardiac diseases (on the basis of physical, ECG, and echocardiographic examinations). Diabetes mellitus was diagnosed according to the recommendations of the American Diabetes Association. ${ }^{18}$ All patients with diabetes had well controlled type 2 diabetes. Their blood glucose concentrations were controlled with diet, oral antidiabetic agents, or both. None of them were receiving insulin treatment. Hypertension was diagnosed according to the common criteria of the World Health Organization and the International Hypertension Association. $^{19}$

\section{Study protocol}

Patients were informed about the study protocol and written consent was obtained from each patient. The recommendations given in the Declaration of Helsinki for guiding physicians in biomedical research involving human subjects were followed. Hypertensive patients discontinued antihypertensive treatment four weeks before undergoing an echocardiographic examination. The treatment of diabetic patients was unchanged.

Transthoracic echocardiography was performed by one of the authors, who was not informed of the patients' clinical data, using a Hewlett-Packard Sonos 1500 instrument (Hewlett-Packard, Andover, Massachusetts, USA) with a 2.5 MHz phased array transducer. The right brachial artery systolic and diastolic pressures were taken as the average of three consecutive measurements immediately after the echocardiographic study with conventional sphygmomanometry. Korotkoff phases I and V were used to determine the systolic and diastolic pressures, respectively.

In 83 study participants who had normal coronary arteriograms, postangiographic treadmill exercise testing or myocardial perfusion scintigraphy was performed to exclude microvascular coronary artery disease. Eleven patients who declined coronary arteriography because of angina underwent myocardial perfusion scintigraphy (seven patients) or treadmill exercise testing (four patients) to exclude coronary artery disease.

\section{Echocardiographic measurements}

Recordings were taken with patients in the left lateral decubitus position. $\mathrm{M}$ mode traces were recorded at a speed of $50 \mathrm{~mm} / \mathrm{s}$ and the Doppler signals at $100 \mathrm{~mm} / \mathrm{s}$. Three consecutive cycles were averaged for every parameter. Left ventricular diameters, left atrial systolic diameter, and left ventricular mass index were also determined from $M$ mode traces recorded from the parasternal long axis view according to established standards. ${ }^{20}$ Ascending aorta diameters were measured from the same view on the $M$ mode tracing at a level $3 \mathrm{~cm}$ above the aortic valve (fig 1). ${ }^{21}$ The systolic diameter was measured at the maximum anterior motion of the aorta and the diastolic diameter was measured at the peak of the QRS complex on the simultaneously recorded ECG.

The peak early transmitral filling velocity during early diastole $(E)$, peak transmitral atrial filling velocity during late diastole (A), deceleration time (time elapsed between peak E velocity and the point where the extrapolated deceleration slope of the E velocity crosses the zero baseline), and isovolumetric relaxation time (time period between the end of mitral diastolic flow Doppler tracing and the beginning of aortic flow Doppler tracing) were used as left ventricular diastolic function parameters. The transmitral diastolic flow Doppler tracing was imaged in the apical four chamber view by using pulsed Doppler echocardiography with the sample volume sited at the tip of the mitral leaflets. The isovolumetric relaxation time was measured on Doppler tracings

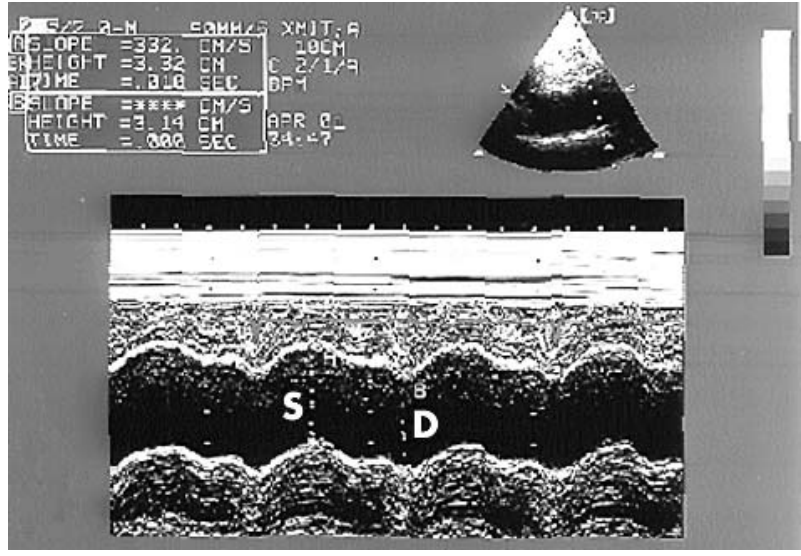

Figure 1 Measurements of systolic (S) and diastolic (D) diameters of the ascending aorta are shown on the $M$ mode tracing obtained at a level $3 \mathrm{~cm}$ above the aortic valve.

obtained in the apical five chamber view with the sample volume placed at the left ventricular outflow tract. The diastolic filling patterns of the study population were classified as normal, abnormal relaxation, pseudonormal, or restrictive pattern. ${ }^{22}$ In $19(21 \%)$ patients with a pseudonormalised pattern of diastolic function, diastolic function parameters were obtained during phase II of the Valsalva manoeuvre. ${ }^{23}$

\section{Calculation of aortic elasticity parameters}

Aortic strain $^{7}$ and distensibility ${ }^{72}$ were used as aortic elasticity parameters. The formulas used to calculate the above mentioned parameters were as follows:

$$
\begin{array}{r}
\text { Aortic strain }(\%)=\begin{aligned}
(\text { aortic systolic diameter }- \text { diastolic } \\
\text { diameter }) \times 100 / \text { diastolic diameter }
\end{aligned} \\
\text { Distensibility }\left(\mathrm{cm}^{2} / \text { dyn }\right)= \\
\begin{aligned}
(2 \times \text { aortic strain }) /(\text { systolic } \\
\text { pressure }- \text { diastolic pressure })
\end{aligned}
\end{array}
$$

\section{Statistical analysis}

Data are expressed as mean (SD). All numeric variables were normally distributed and the variance between the study groups was similar. Thus, the study groups were compared for various numeric parameters by one way analysis of variance and by post hoc Tukey's test for multiple comparisons. Proportions were compared by a $4 \times 2$ cross table and the $\chi^{2}$ test. Differences in aortic elasticity parameters between groups were assessed with two way analysis of variance using the appropriate covariate (plasma cholesterol concentration). A multiple stepwise (forwards and backwards) linear regression analysis was performed for multivariate analysis. The multivariate model consisted of left ventricular diastolic function parameters as dependent variables and of independent variables that had a significant correlation with left ventricular diastolic function parameters in the simple linear regression analysis. Aortic distensibility was the only parameter of aortic stiffness that was entered in the multivariate model. A probability value of $p<0.05$ was considered significant and two tailed p values were used for all statistics. The SPSS 7.5 program for Windows (SPSS Inc, Chicago, Illinois, USA) was used for all statistical calculations.

\section{RESULTS}

\section{Patient characteristics}

Table 1 lists patients' characteristics. The mean (SD) age did not differ significantly between the study groups (50 (10) years in the control group, 55 (8) years in the hypertensive 
Table 1 Clinical and echocardiographic findings of the study groups

\begin{tabular}{|c|c|c|c|c|c|}
\hline & Control $(n=27)$ & $\mathrm{HT}(\mathrm{n}=25)$ & $\mathrm{DM}+\mathrm{HT}(\mathrm{n}=18)$ & DM $(n=24)$ & p Value \\
\hline Women & 16 & 15 & 13 & 15 & NS \\
\hline Age (years) & $50(10)$ & $55(8)$ & 54 (11) & $51(10)$ & NS \\
\hline Smokers & & & & & \\
\hline $\mathrm{PCL}(\mathrm{mmol} / \mathrm{l})$ & $4.8(0.69)$ & $6.05(1.38)^{*}$ & $5.92(1.78)^{*}$ & $5.33(1.46)$ & 0.019 \\
\hline Heart rate (beats/min) & $75(9)$ & $78(12)$ & $80(12)$ & $78(10)$ & NS \\
\hline LVDd (mm) & $46(4)$ & $47(5)$ & $47(6)$ & $43(5)$ & NS \\
\hline Sd (mm) & $30(4)$ & 30 (5) & $0(5)$ & 27 (4) & NS \\
\hline$(\%)$ & $64(7)$ & $68(9)$ & 67 (7) & $67(8)$ & NS \\
\hline LAd (mm) & $33(5)$ & $38(6)^{*}$ & $37(5)^{*}$ & $35(4)$ & 0.008 \\
\hline LVMI $\left(\mathrm{g} / \mathrm{m}^{2}\right)$ & $84(21)$ & $111(37)^{*}$ & $104(31)^{*}$ & $86(21) \dagger \ddagger$ & 0.005 \\
\hline$E / A$ & $1.09(0.24)$ & $0.89(0.21)^{*}$ & $0.81(0.17)^{*}$ & $0.80(0.16)^{*}$ & $<0.001$ \\
\hline DT (ms) & $203(39)$ & $249(54)^{*}$ & $242(42)^{*}$ & $245(51)^{*}$ & 0.006 \\
\hline IVRT (ms) & $85(18)$ & $124(23)^{*}$ & $124(14)^{*}$ & $117(18)^{*}$ & $<0.001$ \\
\hline \multicolumn{6}{|c|}{ 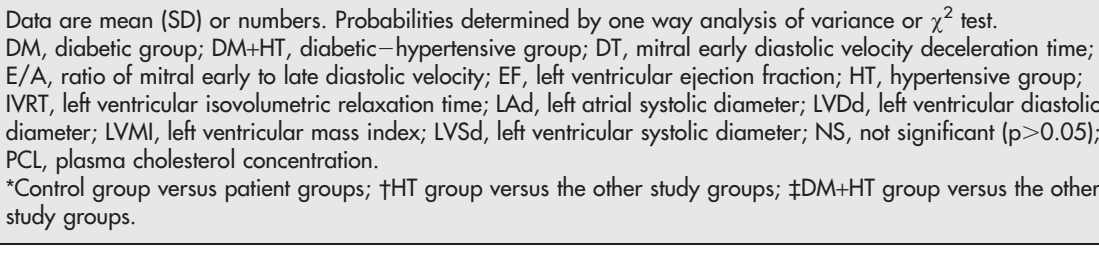 } \\
\hline
\end{tabular}

group, 51 (10) years in the diabetic group, and 54 (11) years in the diabetic-hypertensive group; all $\mathrm{p}>0.05$ ). Plasma cholesterol concentrations were higher in the hypertensive and diabetic-hypertensive groups than in the control group (6.05 (1.38) mmol/l and 5.92 (1.78) mmol/l $v 4.8$ (0.69) $\mathrm{mmol} / \mathrm{l}$, respectively). There were no differences in sex or smoking status between the study groups.

\section{Aortic function parameters}

The highest pulse pressure was obtained in the hypertensive and the diabetic-hypertensive groups. The pulsatile change in the aortic diameter was less in the patient groups than in the control group. Aortic strain and aortic distensibility differed between the patient groups and the control group (table 2). The diabetic-hypertensive group had the most disturbance in aortic elasticity compared with other patient groups (fig 2). There were significant differences in the aortic elasticity parameters between the patient groups and the control group, even after adjustment for plasma cholesterol concentrations $(p<0.001)$.

\section{Left ventricular diastolic function}

In the patient groups, E/A was lower and the isovolumetric relaxation time and the deceleration time were longer than in the control group (table 1). There was no difference between the patient groups in these parameters. The diastolic filling pattern was normal in $39(41 \%)$ patients and pseudonormal in $16(18 \%)$. Relaxation was abnormal in $39(41 \%)$. Figure 3

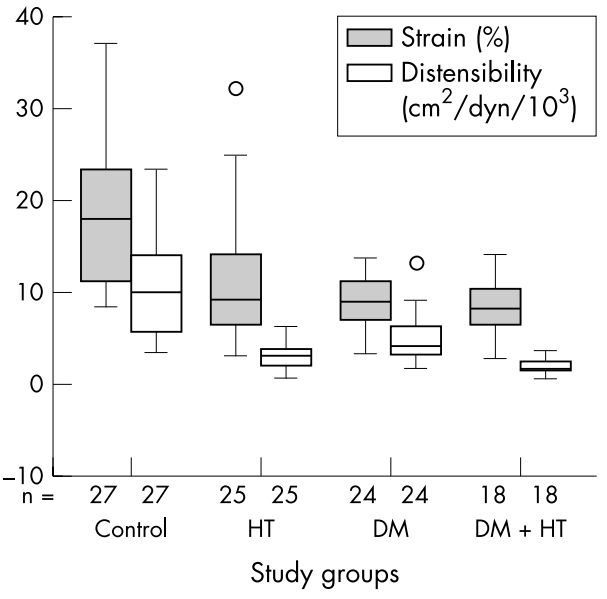

Figure 2 Box plots showing the median and dispersion of aortic strain (grey boxes) and distensibility (open boxes) in the study groups. DM; diabetic group; $\mathrm{DM}+\mathrm{HT}$, diabetic-hypertensive group; $\mathrm{HT}$, hypertensive group. O shows outlier cases.

presents the distribution of diastolic filling patterns in the study groups. The pseudonormal filling pattern was most frequently seen in the diabetic-hypertensive group (hypertensive group $20 \%$, diabetic group 17\%, and diabetic-hypertensive group $39 \%$ ).

Table 2 Aortic stiffness parameters in the study groups

\begin{tabular}{llllll}
\hline & $\begin{array}{l}\text { Control } \\
(\mathbf{n}=\mathbf{2 7})\end{array}$ & HT $(\mathbf{n = 2 5})$ & $\begin{array}{l}\text { DM+HT } \\
(\mathbf{n = 1 8})\end{array}$ & DM (n=24) & p Value \\
\hline SBP (mm Hg) & $113(12)$ & $163(12)^{*}$ & $169(10)^{*}$ & $117(13) \dagger \ddagger$ & $<0.001$ \\
DBP (mm Hg) & $73(9)$ & $91(14)^{*}$ & $84(10)^{*}$ & $75(6) \dagger \ddagger$ & $<0.001$ \\
Pulse pressure (mm Hg) & $40(14)$ & $71(14)^{*}$ & $84(11)^{*}$ & $42(13) \dagger \ddagger$ & $<0.001$ \\
ASD (mm) & $34(4)$ & $37(5)^{*}$ & $35(4)^{*}$ & $33(3) \dagger$ & 0.011 \\
ADD (mm) & $29(4)$ & $33(4)^{*}$ & $33(4)^{*}$ & $30(3)$ & 0.001 \\
PDC (mm) & $5(2)$ & $4(2)^{*}$ & $3(1)^{*}$ & $3(1)^{*}$ & $<0.001$ \\
Aortic strain (\%) & $18(8)$ & $11(7)^{*}$ & $8(3)^{*} \dagger$ & $9(3)^{*} \ddagger$ & $<0.001$ \\
Distensibility $\left(\mathrm{cm}^{2} / \mathrm{dyn} / 10^{3}\right)$ & $10(5.1)$ & $3.1(1.5)^{*}$ & $2(0.9)^{*} \dagger$ & $5.1(2.8)^{*} \dagger \ddagger$ & $<0.001$ \\
\hline
\end{tabular}

Data are mean (SD).

ADD, aortic diastolic diameter; ASD, aortic systolic diameter; AT, descending aortic flow acceleration time; DBP, diastolic blood pressure; PDC, pulsatile diameter change.

${ }^{*}$ Control group versus patient groups; $† H T$ group versus the other study groups; $\ddagger D M+H T$ group versus the other study groups. 


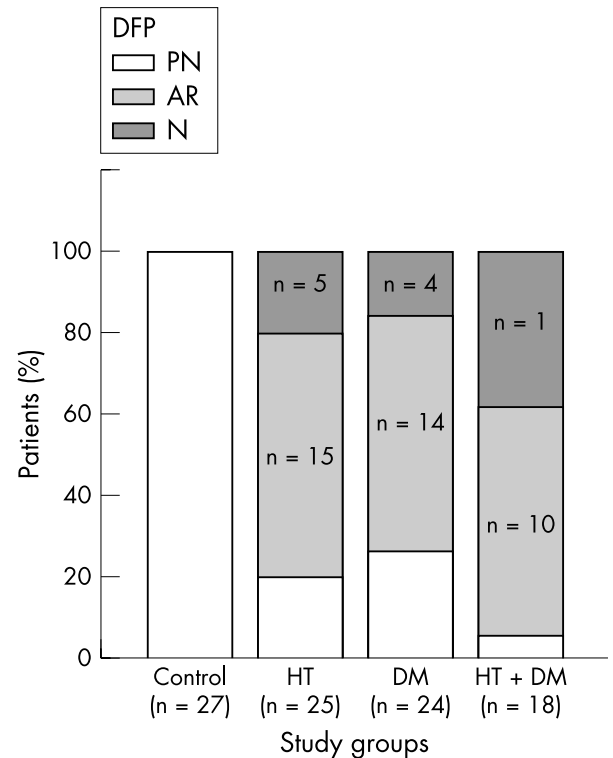

Figure 3 Distribution of diastolic filling patterns within each of the four groups. AR, abnormal relaxation; DFP, diastolic filling pattern; N, normal; PN, pseudonormal.

Although aortic strain (9 (3)\%) and distensibility (3.2 (1.6) $\mathrm{cm}^{2} /$ dyn $/ 10^{3}$ ) in patients with the abnormal relaxation pattern were greater than in those with the pseudonormal pattern $\left(7(4) \%\right.$ and $2.6(2) \mathrm{cm}^{2} / \mathrm{dyn} / 10^{3}$, respectively), these differences were not significant. There were significant differences in aortic strain (17 (8)\%) and distensibility (8.7 (4.8) $\mathrm{cm}^{2} / \mathrm{dyn} / 10^{3}$ ) between patients with the normal pattern and patients with the other two patterns ( $p<0.001$, one way analysis of variance comparisons) (fig 4 ).

\section{Relations between left ventricular diastolic function and various parameters}

Table 3 presents univariate relations of left ventricular diastolic function parameters for both control and patient groups. The isovolumetric relaxation time correlated with age, left ventricular mass index, mean blood pressure, aortic strain (fig 5A), and distensibility in univariate analysis. The $\mathrm{E} / \mathrm{A}$ ratio (fig 5B) and deceleration time (fig 5C) correlated well with aortic strain and distensibility.

In the control group, aortic distensibility was found by multiple stepwise linear regression analysis to be the parameter most closely related to left ventricular diastolic function (table 4). Aortic distensibility was found to be the parameter most closely related to both the E/A ratio

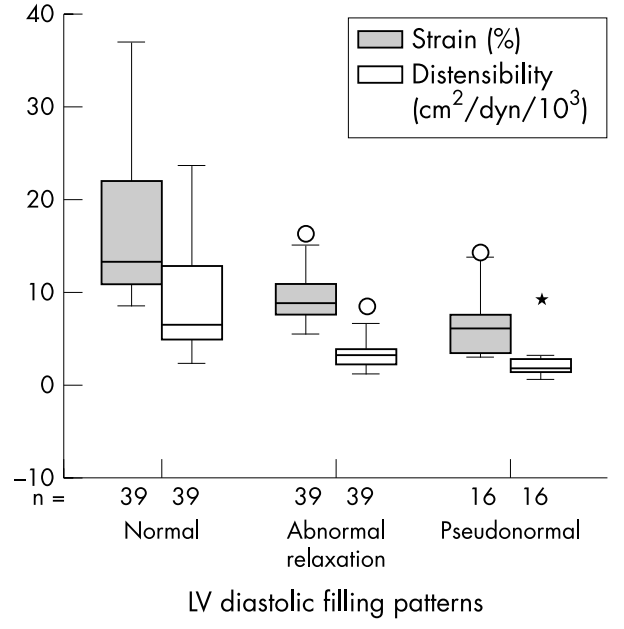

Figure 4 Box plots showing the median and dispersion of aortic strain (grey boxes) and distensibility (open boxes) according to left ventricular diastolic filling patterns. *Extreme cases.

(= $0.9+0.02$ (distensibility), overall $\left.R^{2}=0.27\right)$ and deceleration time $(=233-3.4$ (distensibility), overall $R^{2}=0.25$ ). The parameters most closely related to isovolumetric relaxation time were the left ventricular mass index and aortic distensibility $(=70+0.3$ (left ventricular mass index) -1.3 (distensibility), overall $R^{2}=0.29$ ).

In the patient group, the parameter most closely related to the E/A ratio was aortic distensibility $(=0.7+0.03$ (distensibility), overall $R^{2}=0.14$ ). Aortic distensibility was the parameter found to be most closely related to deceleration time $(=269-6.6$ (distensibility), overall $R^{2}=0.13$ ). The parameters most closely related to isovolumetric relaxation time were aortic distensibility and age $\left(=106-3.7\right.$ (distensibility) +0.5 (age), overall $\left.R^{2}=0.32\right]$ (table 4).

Even though the study group variable (0, control; 1 , hypertensive; 2, diabetic; 3, diabetic-hypertensive) was entered in to the multivariate model, aortic distensibility was found to be the parameter most closely related to the E/A ratio $(=0.9+0.03$ (distensibility) -0.05 (study group variable), overall $\left.R^{2}=0.43\right)$, deceleration time $(=253-5$ (distensibility), overall $R^{2}=0.22$ ), and isovolumetric relaxation time $(=87-2.4$ (distensibility) +5.4 (study group variable $)+0.5($ age $)$, overall $\left.R^{2}=0.53\right)($ table 4$)$.

\section{Reproducibility}

Interobserver reproducibility was assessed on videotape recordings from 15 randomly selected patients. The BlandAltman analysis was used for agreement. The agreement

\begin{tabular}{|c|c|c|c|c|c|c|}
\hline & \multicolumn{3}{|c|}{ Control group ( $n=27$ ) } & \multicolumn{3}{|c|}{ Patient group $(n=67)$} \\
\hline & E/A & DT & IVRT & E/A & DT & IVRT \\
\hline Sex & -0.04 & 0.05 & 0.11 & 0.11 & 0.09 & -0.05 \\
\hline Age & $-0.37^{*}$ & $0.35^{*}$ & $0.39^{*}$ & $-0.25^{\star}$ & $0.31^{*}$ & $0.36^{*}$ \\
\hline Heart rate & 0.03 & -0.03 & 0.03 & 0.03 & -0.12 & 0.04 \\
\hline LVMI & -0.28 & $0.48^{* *}$ & $0.41^{*}$ & -0.12 & $0.31^{*}$ & 0.29 \\
\hline $\mathrm{EF}$ & $0.33^{*}$ & -0.23 & 0.16 & -0.09 & -0.05 & 0.02 \\
\hline Mean BP & -0.16 & 0.15 & $0.38^{*}$ & 0.20 & 0.03 & 0.28 \\
\hline Aortic strain & $0.39^{*}$ & $-0.37^{*}$ & $-0.49^{* *}$ & $0.51^{* *}$ & $-0.40^{* *}$ & $-0.57^{* *}$ \\
\hline Distensibility & $0.51^{* *}$ & $-0.50^{* *}$ & $-0.36^{*}$ & $0.38^{*}$ & $-0.36^{*}$ & $-0.53^{* *}$ \\
\hline
\end{tabular}



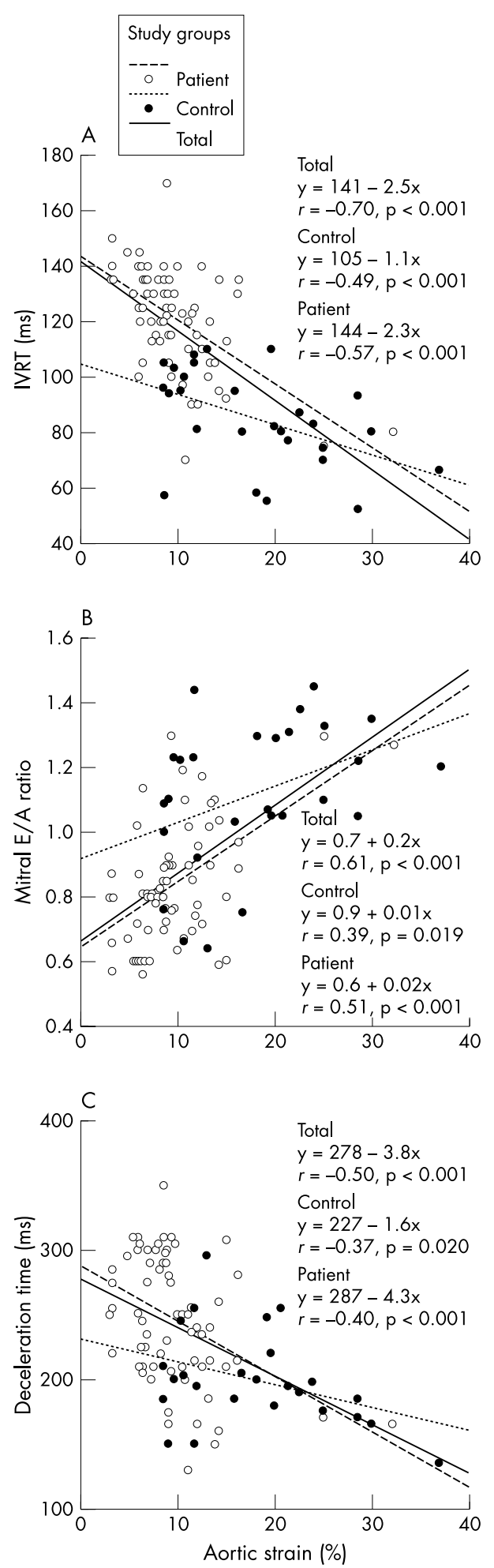

Figure 5 Linear regression curves of the relation between aortic strain and (A) left ventricular isovolumetric relaxation time (IVRT), (B) ratio of mitral early to late diastolic velocity (E/A), and (C) deceleration time in the control group (hatched line), the patient group (dotted line), and total study population (solid line).

between two observers was good for measuring ascending aortic systolic diameter (95\% confidence interval of the difference -1.3 to $0.5 \mathrm{~mm}$, SEE $=0.4 \mathrm{~mm}, \mathrm{p}=0.37$ ) and diastolic diameter (95\% confidence interval of the difference -0.8 to $1.2 \mathrm{~mm}$, SEE $=0.5 \mathrm{~mm}, \mathrm{p}=0.62$ ).

\section{DISCUSSION}

The present study shows that hypertension and diabetes mellitus increase aortic stiffness even in the absence of coronary artery disease and that there is an association between left ventricular diastolic function and aortic stiffness.

\section{Influence of diabetes mellitus and hypertension on aortic stiffness}

Previous studies have shown that hypertension and diabetes mellitus decrease aortic strain and distensibility. ${ }^{1025-28}$ The two stiffness parameters mentioned were calculated from the pulsatile change of the ascending aortic diameter. Ascending aorta elasticity is impaired in patients with coronary artery disease, ${ }^{16}{ }^{17}$ perhaps because this part of the aorta is supplied by the coronary arteries. ${ }^{29}$ The failure of previous studies to take this into consideration may be a limitation affecting their results. In contrast to previous studies, in the present study coronary artery disease was excluded by appropriate methods. Even under these circumstances, our study showed that hypertension and diabetes mellitus lead to an increase in aortic stiffness.

Although the mechanism by which hypertension and diabetes mellitus lead to an increase in aortic stiffness is unclear, the following is one possible explanation. In hypertension, stress is caused by high pressure on the arterial walls, with resulting structural changes and atherosclerosis. ${ }^{27}$ In diabetes mellitus, accumulation of some glycosides in the arterial wall may cause the stiffness. ${ }^{28}$ Whatever the mechanism is, aortic stiffness is associated with high mortality in both hypertensive patients and in patients with diabetes. ${ }^{127}$ The present study, in addition to previous ones, shows that aortic stiffness increases more when accompanied by diabetes mellitus in hypertensive patients. Thus, in patients with both diseases the increase in mortality may be linked to the increase in aortic stiffness. ${ }^{30}$ This theory should be confirmed by future studies.

\section{Relation between aortic stiffness and left ventricular diastolic function}

A notable and hitherto unreported finding of the present study is that there is a relation between left ventricular diastolic function and aortic stiffness in patients with diabetes, hypertension, or both. Previous studies have reported that left ventricular mass and function are linked to aortic stiffness. ${ }^{13}{ }^{31}$ However, some studies obtained the opposite results. ${ }^{15}{ }^{32}{ }^{33}$ Although these studies assessed left ventricular systolic function, none evaluated diastolic function. Recently, Ikonomidis and colleagues $^{34}$ reported a significant univariate relation between aortic distensibility, mitral inflow propagation velocity, and mitral E/A $(r=0.51$ and $r=0.35$, respectively, $\mathrm{p}<0.01)$ in 110 patients with newly diagnosed hypertension. This report was in agreement with our findings.

Although the findings of the present study show the close association between aortic stiffness and left ventricular diastolic function, a causal relation is not certain. There are two possible explanations for this relation: Firstly, parallel changes may occur in the cardiac and aortic walls due to hypertension or diabetes. In other words, left ventricular diastolic dysfunction and aortic stiffness may be epiphenomena of the myocardial and aortic injuries well characterised in diabetes and hypertension. Although in patients with diabetes glycosides accumulate in the myocardium, ${ }^{35}$ it is not known whether the same changes occur in the cardiac and aortic walls in the early stage of this disease. The epiphenomena of myocardial and arterial damage in diabetes and hypertension may not explain the association between left ventricular diastolic function and aortic stiffness in the 
Table 4 Results of multivariate analysis

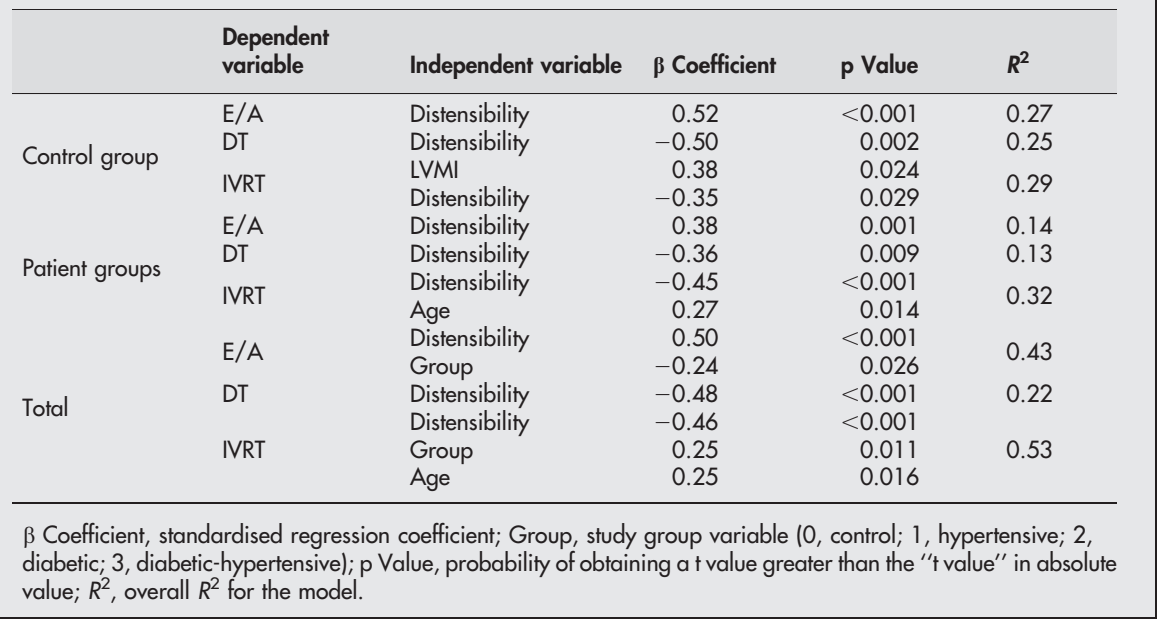

control group. However, high blood pressure or high glucose within the normal range may cause this relation, which is consistent with the idea of an epiphenomenon. Unfortunately, 24 hour blood pressure and haemoglobin Alc were not measured in the control group to optimise the possibility of detecting a relation supporting the hypothesis above. The second possible explanation is that increased aortic stiffness may also increase afterload, inducing myocardial structural changes of the left ventricle and, through that, left ventricular diastolic dysfunction. The most important factor in developing cardiac hypertrophy is increased end systolic wall stress. ${ }^{36}$ End systolic wall stress is influenced not only by the geometric properties of the ventricle but also by aortic stiffness. ${ }^{131}$ To overcome this end systolic stress, structural changes that lead to an increase in systolic and diastolic myocardial stiffness occur in the myocardium. ${ }^{37}$ Thus, this increased myocardial stiffness causes gradual impairment beginning with diastolic dysfunction and progressing to systolic dysfunction. In the present study, there was a significant relation between aortic distensibility and left ventricular mass index in both the control group $(r=-0.41, \mathrm{p}=0.022)$ and the patient group $(r=-0.38$, $\mathrm{p}=0.009$ ). In the control group, the correlation between aortic stiffness and diastolic function was not independent of the correlation between the left ventricular mass index and diastolic function in multivariate analysis. However, in the patient group, the correlation between aortic stiffness and diastolic function was independent of the left ventricular mass index. This may be explained by the occurrence of structural changes causing myocardial stiffness before the development of left ventricular hypertrophy. ${ }^{38}$

In previous studies, there was an increase in cardiac dysfunction with associated hypertension in patients with diabetes. ${ }^{39}$ As our study shows, there is also an increase in aortic dysfunction in these patients. When all study groups were entered in to the multivariate model, aortic stiffness was found to be the parameter most closely related to diastolic function. However, we cannot conclude from our findings that diastolic dysfunction may result from aortic stiffness. To show such a causal relation, the gradual impairment of aortic elasticity and the relation of this gradual impairment to diastolic function, from normal to abnormal, needs to be assessed.

\section{Study limitation}

Coronary arteriography was not performed in 11 patients. In these patients, subclinical coronary artery disease cannot be excluded. On the other hand, it has been reported that coronary flow is not influenced by insignificant coronary artery stenosis. ${ }^{40}$ Therefore, this may not be a limitation of our study.

\section{Conclusion}

There is an increase in aortic stiffness in patients with diabetes and hypertension even after coronary artery disease is excluded. The most interesting finding obtained from the present study is that there is a close association between left ventricular diastolic function and aortic stiffness, but further studies are needed to confirm a causal relation.

\section{Authors' affiliations}

M Eren, S Gorgulu, N Uslu, S Celik, B Dagdeviren, T Tezel, Siyami Ersek Cardiothoracic Surgery Center, Cardiology Department, Istanbul, Turkey

\section{REFERENCES}

1 Arnett DK, Evans GW, Riley WA. Arterial stiffness a new cardiovascular risk factor. Am J Epidemiol 1994;140:669-82.

2 Asmar R, Benetos A, Topouchian J, et al. Assessment of arterial distensibility by automatic pulse wave velocity measurement: validation and clinical application studies. Hypertension 1995;26:485-90.

3 Lehman ED, Parker JR, Hopkins GD, et al. Validation and reproducibility of pressure corrected aortic distensibility measurements using pulse wave velocity Doppler ultrasound. J Biomed Eng 1993;15:221-8.

4 Hallock P. Arterial elasticity in man in relation to age as evaluated by the pulse wave velocity metod. Arch Intern Med 1934:54:770.

5 Sands J. Studies in pulse wave velocity in pathological conditions. Am J Physiol 1925;71:519-33.

6 Della Corte M, Locchi F, Spinelli E, et al. Effect of the anatomical structure of the arterial tree on the measurement of pulse wave velocity in man. Phys Med Biol 1979:24:593-9.

7 Lacombe F, Dart A, Dewar E, et al. Arterial elastic properties in man: a comparison of echo-Doppler indices of aortic stiffness. Eur Heart $J$ 1992:13:1040-5.

8 Devereux RB, Roman MJ, Paranicas M, et al. Impact of diabetes on cardiac structure and function: the strong heart study. Circulation 2000;101:2271-6.

9 Poirier P, Bogaty P, Garneau C, et al. Diastolic dysfunction in normotensive men with well-controlled type 2 diabetes: importance of maneuvers in echocardiographic screening for preclinical diabetic cardiomyopathy. Diabetes Care 2001;24:5-10.

10 Toutouzas K, Stefanadis C, Tsiamis E, et al. Aortic pressure-diameter relation in patients with non-insulin dependent diabetes mellitus: new insights. Diabetologia 2000;43:1070-5.

11 Isnard RN, Pannier BM, Laurent S, et al. Pulsatile diameter and elastic modulus of the aortic arch in essential hypertension: a noninvasive study. J Am Coll Cardiol 1989:13:399-405.

12 Dart A, Silagy C, Dewar E, et al. Aortic distensibility and left ventricular structure and function in isolated systolic hypertension. Eur Heart $J$ 1993;14:1465-70.

13 Bouthier JD, De Luca N, Safar ME, et al. Cardiac hypertrophy and arterial distensibility in essential hypertension. Am Heart J 1985;109:1345-52.

14 Devereux RB, Savage DD, Sachs I, et al. Relation of hemodynamic load to left ventricular hypertrophy and performance in hypertension. Am J Cardiol 1983:51:171-6. 
15 Lartaud-Idjouadiene I, Lompre AM, Kieffer $P$, et al. Cardiac consequences of prolonged exposure to an isolated increase in aortic stiffness. Hypertension 1999;34:63-9

16 Hirai T, Sasayama S, Kawasaki T, et al. Stiffness of systemic arteries in patients with myocardial infarction: a noninvasive method to predict severity of coronary atherosclerosis. Circulation 1989;80:78-86.

17 Stefanadis C, Stratos C, Boudoulas H, et al. Distensibility of the ascending aorta in coronary artery disease and changes after nifedipine administration. Chest 1994;105:1017-23.

18 Anon. Classification and diagnosis of diabetes mellitus and other categories of glucose intolerance. National Diabetes Data Group. Diabetes 1979;28:1039-57.

19 Anon. 1999 World Health Organization-International Society of Hypertension guidelines for the management of hypertension. J Hypertens 1999:17:151-83.

20 Sahn D, DeMaria A, Kisslo J, et al. Recommendations regarding quantification in M-mode echocardiography: results of a survey of echocardiographic measurements. Circulation 1978:58:1072-83.

21 Stratos C, Stefanadis C, Kallikazaros I, et al. Ascending aorta distensibility abnormalities in hypertensive patients and response to nifedipine administration. Am J Med 1992;93:505-12.

22 Rakowski H, Appleton C, Chan KL, et al. Canadian consensus recommendations for the measurement and reporting of diastolic dysfunction by echocardiography: from the Investigators of Consensus on Diastolic Dysfunction by Echocardiography. J Am Soc Echocardiogr 1996;9:736-60.

23 Dumesnil JG, Gaudreault G, Honos GN, et al. Use of Valsalva maneuver to unmask left ventricular diastolic function abnormalities by Doppler echocardiography in patients with coronary artery disease or systemic hypertension. Am J Cardiol 1991;68:515-9.

24 Stefanadis C, Wooley CF, Bush CA, et al. Aortic distensibility in post stenotic aortic dilatation:the effect of co-existing coronary artery diasease. J Cardiol $1988 \cdot 18 \cdot 78-82$

25 Christensen T, Neubauer B. Arterial wall stiffness in insulin-dependent diabetes mellitus: an in-vivo study. Acta Radiol 1987;28:207-8.

26 Oxlund H, Rasmussen LM, Andreassen TT, ef al. Increased aortic stiffness in patients with type 1 (insulin-dependent) diabetes mellitus. Diabetologia 1989:32:748-52.
27 Blacher J, Asmar R, Djane S, et al. Aortic pulse wave velocity as a marker of cardiovascular risk in hypertensive patients. Hypertension 1999;33:1111-7.

28 Brownlee M, Cerami A, Vlassara H. Advanced glycosylation end products in tissue and biochemical basis of diabetic complications. N Engl J Med 1988;318:1315-21.

29 Clarke JA. An $x$-ray microscopic investigation of the vasa vasorum of the human ascending aorta. J Anat 1963;97:630-1.

30 Epstein M, Sowers JR. Diabetes mellitus and hypertension. Hypertension 1992:19:403-18.

31 Nichols WW, O'Rourke MF, Avolio AP, et al. Effects of age on ventricularvascular coupling. Am J Cardiol 1985;55:1179-84.

32 Urschell CW, Covell JW, Sonnenblick EH, et al. Effects of decreased aortic compliance on performance of the left ventricle. Am J Physiol 1968;214:298-304.

33 Kelly RP, Tunin R, Kass DA. Effect of reduced aortic compliance on cardiac efficiency and contractile function of in situ canine left ventricle. Circ Res 1992;71:490-502.

34 Ikonomidis I, Protogerou A, Kotsis V, et al. Arterial stiffness and aortic distensibility are associated with left ventricular diastolic dysfunction in newly diagnosed hypertensive patients [abstract]. Eur J Echocardiogr 2002;3(suppl I):S102

35 Factor SM, Minase T, Sonnenblick EH. Clinical and morphological features of human hypertensive-diabetic cardiomyopathy. Am Heart J 1980;99:446-58.

36 Grossman W, Jones D, McLaurin LP. Wall stress and patterns of hypertrophy in the human left ventricle. J Clin Invest 1975;56:56-64.

37 Weber KT. Cardiac interstitium in health and disease: the fibrillar collagen network. J Am Coll Cardiol 1989;13:1637-52.

38 Di Bello V, Pedrinelli R, Bianchi $M$, et al. Ultrasonic myocardial texture in hypertensive mild-to-moderate left ventricular hypertrophy: $A$ videodensitometric study. Am J Hypertens 1998;11:155-64.

39 Avendano GF, Agarwal RK, Bashey RI, et al. Effects of glocose intolerance on myocardial function and collagen-linked glycation. Diabetes 1999:48: 1443-7.

40 Kranidis Al, Patsilinakos S, Filippatos G, et al. Non-invasive evaluation of coronary reserve: assessment of coronary reserve in patients with coronary artery disease by transesophageal-Doppler echocardiography. Int J Cardiol 1999:68:107-13.

\section{IMAGES IN CARDIOLOGY}

\section{Rhabdomyoma as accessory pathway: electrophysiologic and morphologic confirmation}

A fetus presenting at 34 weeks' gestation with hydrops was diagnosed to have a supraventricular tachyarrhythmia with associated multiple intracardiac rhabdomyomas. After delivery, the patient still suffered from supraventricular tachyarrhythmia and was treated with several antiarrhythmic agents, but without success. At the age of 7 months, there was one large residual tumour on the left atrial aspect of the anterior mitral valve leaflet (panel

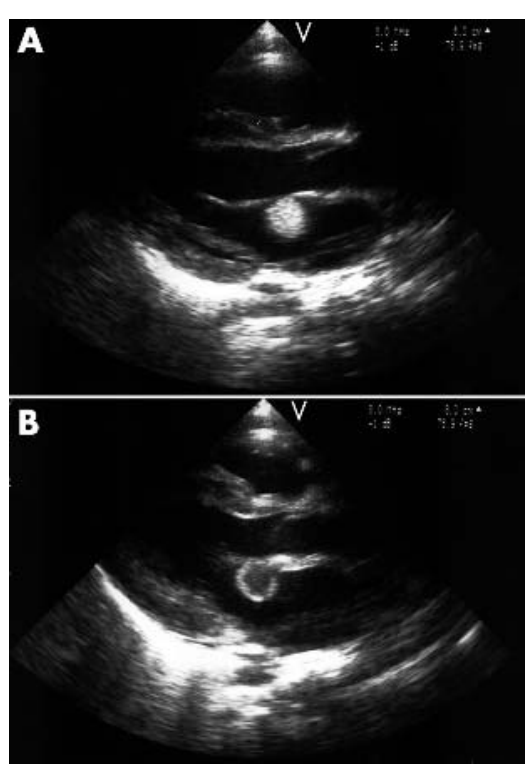

A), with associated pre-excitation and re-entrant supraventricular tachyarrhythmia suggestive of a left sided pathway. During electrophysiology study, catheter ablation was performed retrogradely, on the ventricular aspect of the tumour, with termination of pre-excitation and non-inducibility of tachyarrhythmia. Echocardiography performed 24 hours later also demonstrated morphologic alteration in the tumour, with development of a large central echolucent area (panel B). At follow up eight weeks later, the patient remained without symptoms. We provide a correlation between catheter ablation, disappearance of pre-excitation, and change in tumour morphology, suggesting that the tumour was indeed the accessory pathway.

M Emmel, K Brockmeier, N Sreeram n.sreeram@uni-koeln.de

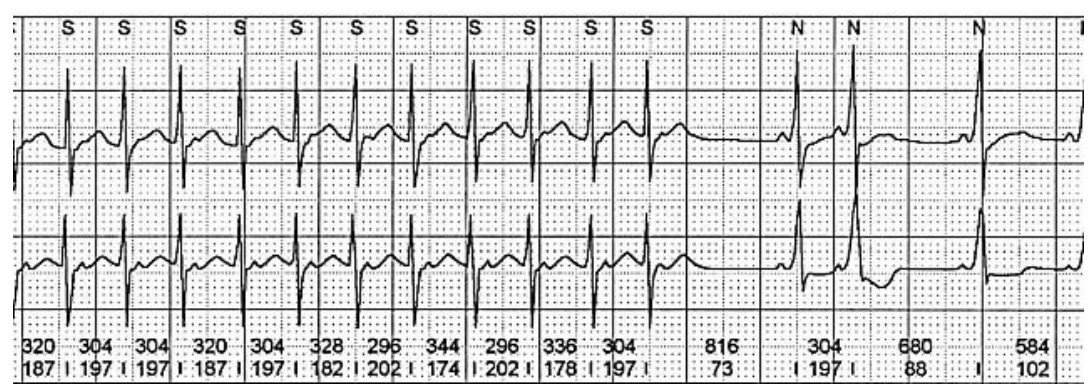

